\title{
Ciberacontecimentos Reflexões etnográficas sobre o extraordinário no mundo on-line
}

\author{
Cyber events
}

Ethnographic reflections on the extraordinary in the on-line world

Airton Luiz Jungblut*

\begin{abstract}
Resumo: Com a emergência do chamado "ciberespaço" através da popularização, em escala global, da comunicação mediada por computador (Internet) surgiu um campo fértil para a Antropologia conduzir suas investigações e, com isso, novas questões teórico-metodológicas passaram a se impor. Tendo em vista este quadro, busca-se aqui contribuir com o enfrentamento reflexivo de alguns dos dilemas do oficio etnográfico no ciberespaço através da avaliação das potencialidades analíticas de determinados tipos de eventos ciberespaciais. Essa avaliação é feita partir do exame de um "acontecimento extraordinário" monitorado etnograficamente pelo autor.
\end{abstract}

Palavras-chave: ciberespaço, internet, ciberacontecimento, método etnográfico

Abstract: Due to the emergence of the so called "cyberspace" through the popularization of communication mediated by computers (Internet) on a global scale, a fertile field for the conduction of investigations in Anthropology arose. As a consequence, new theoretical and methodological issues are made necessary. Aiming at this circumstance, we want to contribute with a reflective approach to some of the dilemmas imposed to the métier of ethnography in the cyberspace by evaluating the analytical potential of some types of cyberspace events. This evaluation is done through the analysis of an "extraordinary happening", ethnographically monitored by the author.

Keywords: cyberspace, internet, cyber event, ethnographic method

Tudo parecia relativamente normal quando terminou em Porto Alegre aquele jogo de futebol ocorrido em 30 de maio de 2007 entre Grêmio e Santos pela $48^{a}$ edição do torneio Libertadores da América. Naquela noite fria de inverno, o Grêmio, time local, havia derrotado por 2 a 0 o Santos na primeira

* Antropólogo, professor e pesquisador no PPG em Ciências Sociais na PUCRS, Porto Alegre, Brasil.<jungblut@pucrs.br>.

\begin{tabular}{|l|l|l|l|l|l|} 
Civitas & Porto Alegre & v. 11 & n. 2 & p. 361-372 & maio-ago. 2011 \\
\hline
\end{tabular}


partida da fase semifinal deste torneio e uma semana após jogaria na casa do adversário, em Santos, a segunda partida. Nada ainda era dado como decidido pois o Santos, que era considerado na época um time superior ao Grêmio, poderia reverter a situação em seus domínios com o apoio emocional de sua torcida. Terminado esse jogo, naquela noite mesmo e nos dias seguintes, passei a monitorar os diálogos que os integrantes das duas torcidas desenvolviam nas suas respectivas comunidades no site de relacionamentos Orkut, site esse muito popular no Brasil. ${ }^{1}$

Nos primeiros momentos, também nada de anormal ali ocorria. Gremistas eufóricos celebravam seu triunfo; santistas preocupados, mas ainda confiantes, tratavam de mobilizarem suas energias emocionais para a revanche que logo ocorreria. No dia seguinte, no entanto, o clima começou a ficar um tanto mais belicoso. Integrantes das comunidades santistas denunciavam supostas violências sofridas por torcedores de seu time que haviam ido a Porto Alegre para assistir o jogo e prometiam retaliações. Segundo informações destes torcedores, cerca de vinte ônibus haviam levado torcedores santistas ao jogo e, na saída do estádio, haviam sofrido ataques de torcedores gremistas sob o olhar complacente da polícia local. Contudo, embora essa informação adicionasse um pouco mais de animosidade à atmosfera da acalorada contenda, ainda se tratava de algo relativamente normal. Hostilidades, desse tipo, são relativamente comuns em jogos futebolísticos no Brasil. A interpretação sobre esses fatos corriqueiros também obedece a um roteiro previsível: as vítimas maximizam os fatos e sua gravidade e os acusados desmentem e/ou os minimizam.

Passados cinco dias, no entanto, um fato novo se somou a esse quadro de beligerância crescente. Na tarde do dia 4 de junho de 2007, nos estúdios de uma pequena rádio popular de São Paulo, a rádio Trianon, entrava no ar o programa "Santos Sempre Santos". Tratava-se de um programa diário, independente, com horário pago, conduzido pelo radialista, advogado e suplente de deputado estadual de São Paulo, Jonas Greb. Torcedor fanático do Santos, esse radialista utilizava esse espaço radiofônico para tratar dos assuntos referentes ao Santos e sua torcida.

Naquele dia Jonas começou seus comentários conclamando os santistas a continuarem acreditando no triunfo do Santos e a dar uma resposta enérgica ao tratamento, em suas palavras, "indigno" recebido por esta torcida dos gremistas e gaúchos (habitantes do estado do Rio Grande do Sul). Conforme sua narrativa de protesto ia se desenvolvendo, os termos usados para se referir

\footnotetext{
1 Nestas comunidades de torcedores, muito ativas em participação, reúnem-se, quando se trata dos principais times brasileiros, algumas centenas de milhares de usuários
} 
aos gremistas e aos gaúchos foram cada vez mais se tornando agressivos. Vejamos alguns trechos de sua fala:

Lá [em Porto Alegre] eles agridem, lá eles batem, eles quebram os vidros dos ônibus.

$[\ldots]$

Essa é a maneira gaúcha de receber as pessoas. Agride quem está no táxi, porque está com a camisa do time que ia jogar com eles na noite. [...] Assim é que o Grêmio trata as pessoas que vão lá.

\section{$[\ldots]$}

Eu acho que gaúcho já tem aquela fama de que gosta de troca-troca, gaúcho não é muito macho e tal. Então eu acho que eles têm que ficar mostrando que são macho [...] batendo nos outros. Deve ser problema psicológico. Esses cara são loucos. Então, veja, o Santos estava lá com vinte ônibus. Todos os vidros dos ônibus foram quebrados, inclusive com a Polícia Militar de lá [...] dando apoio. [...] Jogaram água com mangueira nos torcedores. Então, você imagina um torcedor à $1 \mathrm{~h}$ da manhã, com os ônibus com os vidros quebrados, molhado, tendo que aguentar três graus de temperatura e viajar até São Paulo com o vento, porque não tinha vidro, e molhado.

$[\ldots]$

Olha, é muito triste. Eles dizem que querem separar do Brasil. Separe! Vai virar Argentina! Vai virar o que quiser! Não precisamos do Rio Grande do Sul na bandeira do Brasil. Vai embora! Some! Muda de país, pô! Eles dizem [...]: 'ah, o sul é meu país'. Vai ser outro país! Vai fazer o país das bichona lá! [....] Vai pro inferno. Todo o gaúcho, todo o gremista, vai tudo pros quintos dos infernos. Não serve pra ser brasileiro. Não é gente! Não é gente! São bandidos! Agora eles têm que vir aqui. E eu não quero pregar a violência, não. [...] Mas eu acho que eles têm que sentir o clima de Libertadores. [...] Eles são bandidos, vamos tratá-los aqui, como eles nos trataram lá.

[...]

A diretoria do Grêmio tratou muito mal a diretoria do Santos.

$[\ldots]$

Esses caras não são gente. Esses caras são bandidos. O time do Grêmio é formado por bandido. A Diretoria do Grêmio são bandidos.

$[\ldots]$

Se eles querem dar a vida pra seguir na Libertadores, até que sigam. Se é esse o preço... Agora ficar querendo mostrar que é macho. Ninguém precisa mostrar que é macho, ou é ou não é. Esses caras tem esses vícios de personalidade aí, gosta de homem, o problema é deles. Não precisa vim querer ficar mostrando toda hora, não. Eu estou indignado porque eu conversei com várias e várias e várias pessoas que apanharam, inclusive da polícia. Porque a polícia, 
inclusive, quando o Grêmio fez o primeiro o gol, a polícia começou a zombar com os torcedores do Santos. Aqui não acontece isso. (...) E lá, ao contrário. A polícia além de baixar o cassete incentivava os caras do Grêmio a baterem. É coisa até pra Ministério da Justiça, porque a policia incentivando a violência. E na hora de quebrar os ônibus não tinha policial tomando conta dos ônibus do Santos, não. Deixaram quebrar a vontade.

$[\ldots]$

Esses Gaúchos que vão pros quintos dos infernos. Eles querem fazer do Sul o país deles, mas que sai logo do Brasil! Botaram lá uma estátua do Maradona e escreveram: Maradona melhor que Pelé. Ué, se eles acham isso, problema deles. Quem acha que Tcheco [jogador do Grêmio] joga bola, meu amigo, tem que achar o Maradona melhor que o Pelé mesmo.

Como se tratava de um programa local, com baixa audiência e direcionado apenas a uns poucos torcedores santistas que se dispusessem a sintonizar, às 4 horas da tarde de uma segunda-feira, as ondas da pequena rádio Trianon de São Paulo, esse discurso não teria quase nenhum impacto como acontecimento. Além disso, suas declarações não chegavam e ser destoantes daquela irracionalidade jocosa produtora de bravatas irresponsáveis que caracteriza a forma como a muitos torcedores fanáticos por futebol no Brasil manifestam-se sobre este esporte. Descontado o fato de que eram proferidas por um, aparentementemente, respeitável senhor evangélico presbiteriano de 54 anos que levava sua pacata vida entre sua atividade política, uma carreira de advogado e uma militância como torcedor santista, nada nestas declarações destoava daquela passionalidade utilizada pelo brasileiro típico para tratar desse tema. Era, portanto, um evento que tinha quase tudo para ser desimportante, sem eco, sem impacto algum.

Mas o destino se encarregou de amplificar essa manifestação a níveis impensáveis. Tudo porque o programa de Greb possuía um site de divulgação na Web no qual ficavam disponibilizados os arquivos de áudio de suas edições. No início da tarde do dia seguinte um integrante da comunidade de Orkut, chamada "Torcida Jovem do Santos", ciente desta informação, postou alguns dos principais pontos transcritos do pronunciamento do radialista, bem como o link para se ouvir na Web a integra do programa. Até este momento, no entanto, ainda nada havia transbordado para além do intramuros santista. Era algo ventilado ali, entre os integrantes de apenas uma comunidade santista, sendo que nem era a mais importante e numerosa. Mas quis o destino que essa postagem fosse acessada, em seguida, por um bisbilhoteiro torcedor gremista que ali estava a monitorar os movimentos da torcida rival, coisa muito 
comum no Orkut. Tão logo isso ocorreu, esse torcedor gremista postou na mais numerosa e importante comunidade do Grêmio um tópico denunciando o destempero verbal de Greb. Eis que então, como rastilho de pólvora, as palavras incendiárias do radialista começaram a chegar, primeiro as massas gremistas e depois, rapidamente, ao Estado inteiro. Jornalistas esportivos gaúchos, que observam rotineiramente as comunidades de torcedores de futebol do Rio Grande do Sul, se encarregaram de, via rádio e jornal, fazer chegar ao grande público o que passou a ser considerado um grave ataque xenofóbico ao estado e sua população. Depois, num segundo e imediato momento, dada a repercussão do episódio no Rio Grande do Sul, houve repercussão nacional com várias empresas jornalísticas nacionais noticiando o fato.

Uma série de fatos inusitados se seguiram a este desenrolar de consequências; torcedores gremistas começaram a invadir os vários perfis que Jonas Greb mantinha no Orkut (estranhamente ele mantinha dez perfis idênticos) inundando-os com mensagens com todo tipo de ofensas, ameaças e/ou protestos. Em um de seus perfis ele recebeu em menos de 24 horas cerca cinquenta mil mensagens deste tipo. Nesta empreitada juntaram-se, inclusive, torcedores do Internacional, o rival local. Estes aos gremistas se uniam em um movimento ruidoso, acima das cores clubísticas, pela defesa da honra do Rio Grande do Sul. Com a repercussão na mídia off-line, logo vieram à tona manifestações de representantes formais do Grêmio, de autoridades do Estado, do Ministério Público local e da injuriada Brigada Militar, a corporação militar atacada pelo radialista como conivente com os atos de violência denunciados. Ocorreram manifestações de repúdio ao pronunciamento do radialista seguidas de promessas de processos e interpelações judiciais.

Comentaristas de programas televisivos e radiofônicos, colunistas de jornais, blogueiros, etc. começaram a tematizar o episódio e ecoar ainda mais as suas consequências. Na Internet, em vários sites de relacionamento, chats, webforuns, etc. o assunto fervilhava em nível nacional, dando motivo para as mais diversas manifestações e acalorados debates sobre as varias questões suscitadas pelo episódio.

Logo Greb começou a sofrer as consequências mais imprevisíveis e indesejadas de seu ato. $\mathrm{Na}$ Web o site que divulgava seu programa foi hackeado por torcedores gremistas e ali se publicou todo tipo de insulto possível ao proprietário. Muitas das pessoas (vários deles evangélicos) que faziam parte de sua rede de amigos no Orkut foram assediados de forma insultuosa pelos detratores de Greb com a intenção de destruir sua reputação. Em muitos pronunciamentos anônimos na Internet ele foi "jurado de morte", caso viesse ao Rio Grande do Sul. Seu programa radiofônico logo saiu do ar devido ao 
cancelamento unilateral de contrato imposto, em razão deste episódio, pela administração da Rádio Trianon. Greb ainda seria alvo, como advogado, de um pedido de abertura de procedimento de interpelação por atitude antiética junto a Ordem dos Advogados do Brasil. Foi, também, processado judicialmente por, pelo menos, quatro cidadãos riograndenses que, por se sentirem atacados em sua honra pelo pronunciamento de Greb, exigiam retratação e/ou indenização.

Fica claro que este episódio se desenvolve através de um interessante influxo recíproco de fatos que ocorrem alternadamente, mas também simultaneamente, no mundo off-line e on-line. Trata-se, como se viu, de uma sucessão curiosa de acidentes causais que subvertem de maneira muito impactante um conjunto amplo de rotinas. Um discurso desastrado utilizando aquilo que Goffman chama de "linguagem de bastidores" vaza acidentalmente para uma zona de "fachada" (Goffman, 1999, p. 120-21) onde, devido a inaceitabilidade de seus termos e lógicas para esta zona, provoca uma avalanche de repercussões avassaladoramente perplexizantes. O que se assiste, posteriormente, é toda uma sorte de ações sociais de reação e de reflexão onde diversas das questões suscitadas pelo acontecimento são tematizadas. No ciberespaço, mais precisamente, esse acontecimento e as questões por ele suscitadas ressonaram de muitas formas, provocando todo tipo de manifestações. Muitos foram os tópicos de discussão deles decorrentes: a violência no futebol, a irracionalidade das torcidas, a xenofobia, a homofobia, o separatismo sulista, a responsabilidade social dos profissionais dos meios de comunicação, a moralidade dos evangélicos, a honra e a hombridade dos gaúchos, as diferenças regionais brasileiras, as afinidades entre Rio Grande do Sul e Argentina, as comparações entre o futebol de Pelé e Maradona, etc.. Ou seja, tal como um fato social total, muito do que precisa ser dramatizado reflexivamente pelos brasileiros, em geral, e pelos gaúchos, em particular, encontrou através deste acontecimento formas de manifestação.

Creio que acontecimentos extraordinários como estes só podem ser observados em toda a complexidade de seus inusitados desdobramentos a partir de locais muito privilegiados e através de condições muito especiais. Neste caso, relatado, só foi possível acompanhar a sucessão curiosa de eventos que o constituíram através de uma incessante e frenética viagem hipertextual na Internet, que só pode ser individual e circunstanciada. Esta viagem tinha, necessariamente, que ser constante e ocorrer durante o período em que os fatos aconteciam, pois, caso contrário, alguns nós importantes dos encadeamentos causais ficariam invisibilizados ao analista.

No ciberespaço assiste-se a um constante dramatizar de acontecimentos como este. Na verdade, muitos de seus habilitantes para ali afluem 
cotidianamente em busca de acontecimentos que quebrem com a monotonia do ordinário e façam jorrar torrencialmente consequências imprevistas e mobilizadoras de atenção. Mas a Antropologia está preparada para lidar com "acontecimentos extraordinários" desta natureza? Um olhar rápido sobre a tradição antropológica nos mostra que essa disciplina nunca escondeu seu fascínio pelo ordinário, pelo regular, pela rotina, pelo previsível. Talvez isso se deva ao fato de que os antropólogos ao buscarem compreender "o outro" em sua exoticidade fatalmente tiveram que apreendê-la em sua regularidade e não nas possíveis formas excêntricas de suas manifestações.

Roberto Cardoso de Oliveira já havia notado essa inclinação da Antropologia para a focalização da normalidade, dos aspectos ordeiros da vida social e cultural dos grupos humanos. Assim teria sido, segundo ele, até, pelo menos, a emergência da antropologia interpretativa norte-americana. Em seu já clássico texto "A categoria de (des)ordem e a pós-modernidade da antropologia" (1988), o autor afirma que as grandes tradições antropológicas, anteriores a esse movimento desencadeado por Clifford Geertz, nada mais foram do que "paradigmas da ordem". Buscando debruçar-se sobre coisas como princípios de organização social (solidariedade mecânica e solidariedade orgânica), estruturas sociais, formas elementares, estruturas elementares, padrões ou regularidades sociais, etc. essas escolas teriam, "impensadamente" adotado a "ordem" como eixo ordenador de seus exercícios analíticos:

Tal a força dessa categoria [- a 'ordem' -] no universo da disciplina que ela não apenas orienta o discurso das diferentes 'escolas', o que constituiria a bem dizer o impensado da disciplina, como ainda manifesta-se no centro de sua problemática, largamente explicita em todos os índices ou sumários de quantos ensaios e monografias a antropologia conhece em sua história (Oliveira, 1988, p. 93).

Oliveira atribui à antropologia interpretativa de Geertz e seus seguidores "pós-modernos" - George Markus, Michel Fischer, James Clifford, Stephen Tyler, Paul Rabinow e Vicent Crapanzano - a iniciativa de terem provocado a emergência de forças que causam "desordem" na narrativa antropológica como a valorização de uma relação de intersubjetividade entre o universo cultural do pesquisador e do pesquisado, do reconhecimento da individualidade que caracteriza o olhar do pesquisador, bem como da historicidade implicada no exercício etnográfico, forças essas que dificultariam enormemente a atitude domesticadora das narrativas antropológicas mais tradicionais.

Ocorre, contudo, que mesmo que sejam adotadas tais posturas desdomesticadoras no exercício etnográfico, isso não garante que o foco 
de interesse de antropólogos com essa orientação deixe de privilegiar as normalidades, os fluxos sociais rotinizados, a monotonia das regularidades cotidianas a serem fixadas, como propõe Geertz numa "forma inspecionável" (Geertz, 1989, p. 29). Pode-se, muito bem, usar toda essa "desordem" metodológica para tratar de coisas bem regulares, como parece propor Geertz:

Compreender a cultura de um povo expõe a sua normalidade sem reduzir a sua particularidade. (Quanto mais eu tento seguir o que fazem os marroquinos, mais lógicos e singulares eles me parecem.). Isso os torna acessíveis: colocá-os no quadro de suas próprias banalidades dissolve a sua opacidade (Geertz, 1989, p. 24).

Em síntese, mesmo em suas versões mais indóceis para com a "ordem” a Antropologia mostra-se uma disciplina que dedica-se muito mais a inventariar o ordinário do que o extraordinário da vida social e cultural.

Situação inversa vive a História. Os historiadores, tradicionalmente, conseguem lidar melhor com acontecimentos extraordinários, pois durante muito tempo foram estes episódios - de grande, de média e até de pequena relevância histórica - seus objetos privilegiados. Só recentemente é que, por aproximação à Antropologia, passaram a se interessar pela "história do cotidiano", a história dos fatos rotineiros da vida das sociedades do passado. Mas, mesmo com esses "ventos", alguns historiadores contemporâneos têm coisas interessantes a dizer sobre "acontecimentos", ou seja, sobre episódios atípicos que habitam e "marcam" a história. Pierre Nora, por exemplo, nos adverte sobre a natureza moderna e ocidental disso que chamamos de “acontecimentos" fornecendo assim uma pista quiçá útil para explicar a pouca presença desses episódios nas narrativas antropológicas - grande parte delas, como se sabe, tematiza sociedades tradicionais e/ou não-ocidentais. Nora faz essa observação contrapondo a situação moderna ao que ocorreria nas sociedades tradicionais:

[nas sociedades tradicionais] os poderes instituídos, as religiões estabelecidas tendiam a eliminar a novidade, a reduzir seu poder corrosivo, a digeri-la através do rito. Todas [essas] sociedades procuram dessa forma perpetuar-se por um sistema de novidades que têm por finalidade negar o acontecimento, pois o acontecimento é precisamente a ruptura que colocaria em questão o equilíbrio sobre o qual elas são fundamentadas. Como a verdade o acontecimento é sempre revolucionário, o grão de areia na máquina, o acidente que 
transforma e que prende inesperadamente. (...) Mas para exorcizar o novo há dois meios: conjurá-los através de um sistema de informação sem informações, ou integrá-lo ao sistema da informação (Nora, 1976, p. 187).

Já Paul Veyne, outro historiador, chama atenção para o exercício necessariamente perspectivista da enunciação de um acontecimento, ao mesmo tempo em que alerta para os tipos de "materiais" (homens e coisas) que devem interagir nestes episódios:

Os acontecimentos não são coisas, objetos consistentes, substâncias;
eles são um corte que realizamos livremente na realidade, um
aglomerado de procedimentos em que agem e sofrem substâncias
em interação, homens e coisas. Os acontecimentos não apresentam
uma unidade natural; não se pode, como o bom cozinheiro de Fedro,
cortá-los conforme suas articulações, pois eles não as possuem
(Veyne, 1982, p. 30).

Teóricos da Comunicação Social também têm se dedicado a reflexão sobre os aspectos conceituais da noção de "acontecimento". O interesse dos comunicólogos por esse tema emerge naturalmente quando estão a abordar o tratamento noticioso dado pelas mídias a esses episódios. É comum nessas abordagens a referência a determinações culturais que operariam na transformação de um acontecimento em uma "notícia". Assim, quando um "acontecimento" é transformado em uma ecoante "notícia", e esta retroalimenta o primeiro, estaria em operância um enquadramento cultural envolvente fornecedor dos parâmetros necessários ao desenvolvimento desse processo. Segundo Eduard Hall essa cultura envolvente, no final das contas, "é que decide em que nós devemos prestar atenção e o que devemos ignorar" (Hall apud Alsina, 2009: p 115). Isso ocorreria animado por uma lógica econômica: "não podemos considerar tudo quanto temos em volta como algo significativo, pois não seriamos capazes de processarmos tanta informação" (Alsina, 2009, p. 115).

Complementarmente, há também neste campo disciplinar quem lembre do caráter "irruptivo" dos acontecimentos. Mesmo que a cultura envolvente forneça de antemão os enquadramentos semânticos necessários a sua ocorrência e posterior assimilação, há sempre no acontecimento algo totalmente novo, momentaneamente assistêmico, imprevisível. O fato é que sua súbita eclosão só seria possível em decorrência de uma associação muito particular e incidental de eventos em um contexto imprevisto de fluxo informacional. Segundo Blaise 
Lempen "o acontecimento é o resultado da brutal ligação de um fato com outros fatos, anteriormente isolados uns dos outros, através da informação" (Lempen, 1980, p. 50).

Mais recentemente, estudiosos da comunicação têm, também, mostrado atenção para acontecimentos ambientados no ciberespaço. E ai há que se fazer menção ao termo cunhado por Rafael Diaz Arias: ciberacontecimentos. Esse termo daria conta daqueles episódios em que há "propagação explosiva de informação" no ciberespaço causada pela divulgação de fatos com grande capacidade de mobilização de atenção através, quase sempre, de material visual, sonoro ou audiovisual (Arias, 2008).

Como se vê, há recursos teóricos interessantes disponíveis nessas disciplinas irmãs que podem ajudar a sanar lacunas existentes na Antropologia. Uma análise antropológica de acontecimentos ciberespaciais passa, portanto, por esse tipo de prospecção interdisciplinar. Com o que se recolheu aqui, é possível, então, sugerir algumas leituras sobre o ciberacontecimento relatado no início deste artigo.

Tratou-se, como se viu, de um episódio em que ficou bastante evidenciada a imprevisibilidade de seu processamento, deste seu ato deflagrador até suas consequências mais tardias. A possibilidade do pronunciamento de Jonas Greb desencadear a sucessão de efeitos em cadeia ocorridos parecia bem pequena. Desafortunadamente, contudo, um estreito caminho (link) se produziu ligando o lugar de onde seus pronunciamentos - potencialmente comprometedores eram impunemente feitos ao lado de fora de seu círculo de atuação. Assim, num determinado "lugar" e momento, onde estavam presentes os atores capazes e interessados em dar àqueles pronunciamentos um eco indesejável ao seu autor, se produziu a faísca que eletrizou um circuito virtual que ninguém imaginaria existir. Um mundo social era criado ali.

A primeira constatação é que a acidentalidade que caracteriza esse processo desempenha um papel importantíssimo na popularidade deste ciberacontecimento. Coisas que desastradamente emergem do privado para o público costumam produzir muito eco no ciberespaço, ainda mais se forem mobilizadoras de atenção (polêmicas) e tiverem como suporte uma rede de atores atuantes e de recursos favorecedores desse eco. Inventariar etnograficamente as condições em que ocorrem esse contrabando informacional, essa intrusão acidental do público no privado, bem como as recompensas que estimulam os que celebram tal processo, parece ser uma boa receita para compreender essa alta impactabilidade social de que se fala. Isso deve ser feito tendo em vista os parâmetros culturais que estruturam o interesse social dramatizado através do acontecimento em questão. 
A segunda constatação é que esse circuito produziu em pouco tempo uma intrincada rede inter e hipertextual que os consumidores deste episódio podiam explorar freneticamente. Com um pouco de atenção nos locais onde o episódio era discutido (blogs, foruns, sites de relacionamento, etc.) podia-se descobrir múltiplos caminhos que permitiam transitar por um circuito que incluía, entre outras coisas, o site hackeado de Greb, seus dez perfis de Orkut, os videos no Youtube onde não somente ecoava o áudio de seu discurso-encrenca mas, também, montagens jocosas que exploravam seu desastre. Assim, o desenrolar do episódio ocasionou a emergência de um denso circuito de atores, materiais (imagens, sons, sites, arquivos, etc.), lugares ciberespaciais, etc.. Circuito esse que se retro-alimentava pelos efeitos por ele produzidos, tanto no mundo online como no off-line.

Tendo em vista esse quadro, penso que um ciberacontecimento como esse mostra-se interessantemente etnografável se o tratarmos como um constructo social, ou seja, como algo que guarda algum grau de similaridade como uma organização social, tal como um partido político, uma igreja ou um clube de futebol. Assim procedendo, pode-se fazer indagações que permitem jogar interessantes luzes sobre o mundo social que se cria através de um ciberacontecimento como o que foi analisado aqui: quais negociações e percepções de realidade ali ocorrem? que tipos de engajamentos identitários ele suscita nos atores que o experimentam? Qual a tessitura das relações sociais que ele suscita? Não devemos deixar que sua efemeridade enquanto acontecimento nos cegue para a sua capacidade de desencadear comportamento militante, compartilhamentos sociais de percepções da realidade, mapeamentos de alianças e rivalidades, etc muito próximos daqueles experimentados em vínculos com organizações formalmente institucionalizadas. No mundo moderno-contemporâneo, descrito por muitos analistas como dissolvente de vínculos identitários fortes (classe, etnia, religião, etc.), talvez devêssemos buscar também em experiências desse tipo o inventário das modalidades atuais de vínculo social.

\section{Referencias}

ALSINA, Miguel R. A construção da notícia. Petrópolis: Vozes, 2009.

ARIAS, Rafael D. La formacion de la realidad: notícia, acontecimiento midiático, ciberacontcimiento. Paper apresentado no III Congresso de Periodismo en la Red. Madrid, 2008.

GEERTZ, Clifford. A interpretação das culturas. Rio de Janeiro: Zahar, 1989.

GOFFMAN, Erving. A representação do eu na vida cotidiana. Petrópolis, Rio de Janeiro: Vozes. 1999. 
LEMPEN, Blaise. Iinformation et pouvoir: essai sur le sens de l'information et son enjeu politique. Lausanne: L'Age de l'homme, 1980.

NORA, Pierre. O retorno do Fato. In: LE GOFF, Jacques (Comp.). História: novos problemas. Rio de Janeiro: Francisco Alves Ed., 1976. p 179-193.

OLIVEIRA, Roberto Cardoso de. A categoria de (des)ordem e a pós-modernidade da antropologia. In: OLIVEIRA, Roberto Cardoso de. Sobre o pensamento antropológico. Rio de Janeiro: Tempo Brasileiro/CNPq, 1988. p. 91-107.

VEYNE, Paul M. Como se escreve a História. Brasília: Editora da UnB, 1982. 